\title{
Voltammetric Studies of the Mechanism of the Oxygen Reduction in Alkaline Media at the Spinels $\mathrm{Co}_{3} \mathrm{O}_{4}$ and $\mathrm{NiCo}_{2} \mathrm{O}_{4}$
}

\author{
Turgut Sönmez, ${ }^{\text {a }}$ Stephen J. Thompson, ${ }^{\mathrm{a}}$ Stephen W. T. Price, ${ }^{\mathrm{b}}$ Derek Pletcher, ${ }^{\mathrm{a}, *}$ \\ and Andrea E. Russell ${ }^{\mathrm{a}, \mathrm{z}}$ \\ ${ }^{a}$ Chemistry, University of Southampton, Southampton SO17 1BJ, United Kingdom
${ }^{b}$ Diamond Light Source Ltd, Diamond House, Harwell Science and Innovation Campus, Didcot,
Oxfordshire OX11 ODE, United Kingdom
}

\begin{abstract}
The mechanism of $\mathrm{O}_{2}$ reduction at the spinels, $\mathrm{Co}_{3} \mathrm{O}_{4}$ and $\mathrm{NiCo}_{2} \mathrm{O}_{4}$, in $\mathrm{KOH}$ electrolyte is probed using voltammetry at rotating disc and rotating ring-disc electrodes by examination of the rotation rate dependent limiting currents. The analysis shows that the products and mechanisms at the two spinels are quite different. At the cobalt spinel, a substantial amount of the $2 \mathrm{e}^{-}$reduction product, $\mathrm{H}_{2} \mathrm{O}_{2}$, is formed while at $\mathrm{NiCo}_{2} \mathrm{O}_{4}$ the $4 \mathrm{e}^{-}$reduction strongly predominates. In terms of both the overpotential for reduction and its limiting current density, the mixed spinel is a substantially better electrocatalyst. It is proposed that the differences arise from an enhanced rate of $\mathrm{O}-\mathrm{O}$ bond cleavage early in the reduction process at $\mathrm{NiCo}_{2} \mathrm{O}_{4}$.

(C) The Author(s) 2016. Published by ECS. This is an open access article distributed under the terms of the Creative Commons Attribution 4.0 License (CC BY, http://creativecommons.org/licenses/by/4.0/), which permits unrestricted reuse of the work in any medium, provided the original work is properly cited. [DOI: 10.1149/2.0111610jes] All rights reserved.
\end{abstract}

Manuscript submitted May 2, 2016; revised manuscript received July 25, 2016. Published August 3, 2016.

Electrocatalysts that can support both oxygen reduction and oxygen evolution at high current densities are critical components of proposed metal/air secondary batteries and reversible fuel cells. The development of such electrocatalysts (and gas diffusion electrodes) provides additional challenges to electrodes designed for only one of these electrode reactions (as in fuel cells and water electrolysers respectively). Spinels and perovskites have been widely proposed as bifunctional oxygen electrocatalysts in concentrated alkaline solutions. ${ }^{1-5}$

In general, of course, cathodic oxygen reduction is a widely studied reaction. ${ }^{1,6}$ It is clearly a multistep reaction and both the products and the overpotential for the reaction depend strongly on the cathode material. It is accepted that the reduction can occur by a number of pathways, see Figure 1.,8 The direct $4 \mathrm{e}^{-}$reduction pathway is envisaged to result from mechanisms where there is cleavage of the $\mathrm{O}-\mathrm{O}$ bond early in the reaction sequence, while the alternative pathways involve $2 \mathrm{e}^{-}$steps with hydrogen peroxide either as the final product or as an intermediate further reduced or undergoing chemical disproportionation. The rate of the further reduction and chemical decomposition of hydrogen peroxide depends strongly on the cathode and reaction conditions. For energy storage applications, it is important that oxygen undergoes the full $4 \mathrm{e}^{-}$reduction because (a) the equilibrium potential of the $\mathrm{O}_{2} / \mathrm{H}_{2} \mathrm{O}$ couple is positive to that for the $\mathrm{O}_{2} / \mathrm{H}_{2} \mathrm{O}_{2}$ couple leading to a higher battery voltage, (b) the current density at any potential is twice as large, and (c) the energy storage capability/mole of oxygen is double. However the observation of a $4 \mathrm{e}^{-}$reduction alone does not distinguish two reaction pathways, the direct $4 \mathrm{e}^{-}$reduction and the $2 \times 2 \mathrm{e}^{-}$reduction where further reaction of $\mathrm{H}_{2} \mathrm{O}_{2}$ is rapid.

In contrast to oxygen evolution, studies of oxygen reduction at $\mathrm{Co}_{3} \mathrm{O}_{4}$ and $\mathrm{NiCo}_{2} \mathrm{O}_{4}$ are not extensive. Moreover, in most papers graphitic carbon powder is present in the catalyst composition ${ }^{9-15}$ and this can confuse studies of $\mathrm{O}_{2}$ reduction since graphitic carbon offers an alternative reaction surface and it is known to influence the response. ${ }^{9-11}$ It is also not a viable component of bifunctional oxygen electrodes because of possible corrosion in the conditions of oxygen evolution. Three recent papers from our group ${ }^{16-18}$ report oxygen reduction at GDE based on $\mathrm{NiCo}_{2} \mathrm{O}_{4}$ catalyst without graphitic carbon. A number of papers have also reported the behavior of nanostructured $\mathrm{Co}_{3} \mathrm{O}_{4}$ and $\mathrm{NiCo}_{2} \mathrm{O}_{4}$ for oxygen reduction ${ }^{12,13,19-32}$ but the assessment of these data is often hampered by the absence of data at 'standard' surfaces, such as Pt, graphitic carbon, or the uncoated glassy carbon surface, for comparison. The inclusion of such standard surfaces enables accurate comparison of the limiting currents and onset potentials

\footnotetext{
*Electrochemical Society Fellow.
}

${ }^{\mathrm{z} E}$-mail: a.e.russell@ soton.ac.uk for the reactions and eliminates the variability related to the use of different reference electrodes.

An exploration of the literature, however, shows that there are a number of issues related to oxygen electrochemistry at $\mathrm{Co}_{3} \mathrm{O}_{4}$ and $\mathrm{NiCo}_{2} \mathrm{O}_{4}$ catalysts, especially in regards to the reduction of oxygen, that have not been fully addressed and these will influence the performance of electrodes with spinels or perovskites as catalysts during battery operation. The aim of this paper is to address these issues using rotating disc electrode experiments with the spinels, $\mathrm{Co}_{3} \mathrm{O}_{4}$ and $\mathrm{NiCo}_{2} \mathrm{O}_{4}$, through analysis of the rotation dependent limiting currents for oxygen reduction and hydrogen peroxide oxidation and reduction. The catalysts are investigated using bound films on an inert (vitreous carbon) rotating disc electrode (RDE) ${ }^{33}$ and the results are compared to those obtained at the standard Pt and graphitic carbon electrodes mentioned above.

\section{Experimental}

Instrumentation.-All electrochemical experiments were carried out with Autolab PGSTAT instruments with NOVA and GPES software packages. The rotation rates of the electrodes were controlled by Pine Instrument Rotators, type CPR or MSR. Scanning electron microscopy (SEM) images of the deposits were obtained with a Philips XL30 ESEM environmental scanning electron microscope operating in the wet mode with a secondary electron (SE) detector and fitted with an EDAX International Phoenix 2 EDX. Transmission electron

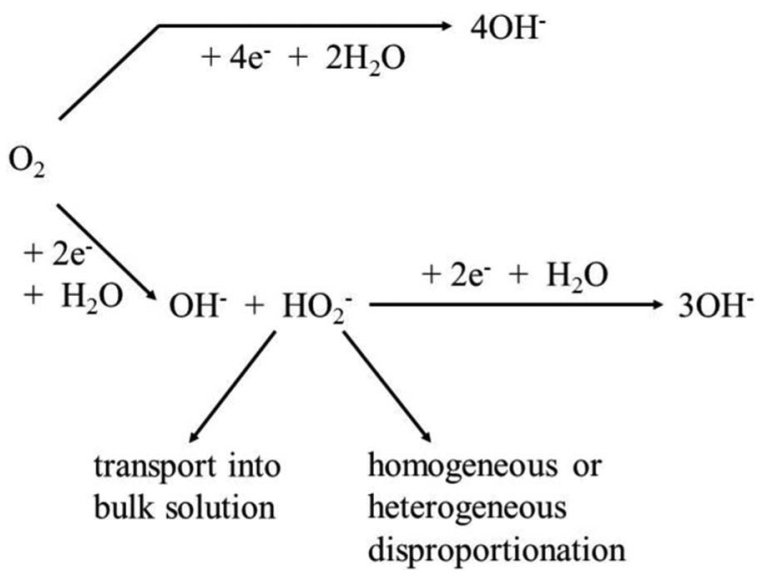

Figure 1. Pathways for cathodic $\mathrm{O}_{2}$ reduction in aqueous alkaline media, based on References 7 and 8. 


\begin{tabular}{|c|c|c|c|c|}
\hline Powder & $\begin{array}{l}\text { Crystal } \\
\text { system }\end{array}$ & $\begin{array}{l}\text { Space } \\
\text { group }\end{array}$ & $\begin{array}{l}\text { Lattice constant } \\
\qquad a=b=c(\AA)\end{array}$ & $\mathrm{V}\left(\AA^{3}\right)$ \\
\hline $\mathrm{Co}_{3} \mathrm{O}_{4}$ & cubic & $\mathrm{fd} 3 \mathrm{~m}$ & 8.09 & 530 \\
\hline $\mathrm{NiCO}_{2} \mathrm{O}_{4}$ & cubic & $\mathrm{fd} 3 \mathrm{~m}$ & 8.11 & 533 \\
\hline
\end{tabular}

microscopy (TEM) images were recorded on either an FEI Tecnai 12 $\left(\mathrm{Co}_{3} \mathrm{O}_{4}\right)$ or JEOL JEM-2100 $\left(\mathrm{NiCo}_{2} \mathrm{O}_{4}\right)$ microscope using samples drop coated onto a $\mathrm{Cu}$ grid (1000 mesh holey carbon, VWR) and an accelerating voltage of $200 \mathrm{kV}$. X-ray diffraction data were collected

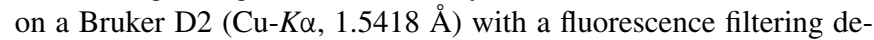
tector. Structural refinement of the XRD data (Table I) was completed using the Rigaku PDXL and Rietveld analysis was conducted using the GSAS software packages. Brunauer, Emmett and Teller (BET) surface area measurements employed a Micromeritrics - Gemini instrument.

Electrochemical cells and electrolyte.-Experiments with rotating disc and ring disc electrodes were carried out in beaker cells (volume $\sim 200 \mathrm{~cm}^{3}$ ) with a polymer cover and a water jacket through which water with a known temperature (generally $298 \mathrm{~K}$ ) was passed. The counter electrode was a Pt gauze in the same compartment and the reference electrode a laboratory fabricated $\mathrm{Hg} / \mathrm{HgO} / \mathrm{KOH}(1 \mathrm{M})$ electrode (potential $+866 \mathrm{mV}$ vs NHE) inside a Luggin capillary. The glassy carbon rotating disc electrode (area $0.2 \mathrm{~cm}^{2}$ ) was a Pine Instruments AF3M electrode. The rotating ring disc electrode had a glassy carbon disc and Pt ring (Pine Instruments AFE7R9GCPT) with a collection efficiency of 0.37 . Prior to each experiment, the electrodes were polished on microcloths (Buehler) with alumina slurries of $1.0 \mu \mathrm{m}$ then $0.05 \mu \mathrm{m}$ particle size. Unless otherwise stated, the electrolyte was $1 \mathrm{M} \mathrm{KOH}$ pre-saturated with oxygen (BOC) prior to each measurement, which included repeating the saturation between measurements at different rotation rates. A blanket of $\mathrm{O}_{2}(\mathrm{~g})$ was maintained over the electrolyte during the measurements and data for at least three replicates of each measurement were obtained. The reproducibility between measurements was $\pm 2 \%$ of the measured current densities.

Preparation of spinels and electrode coatings. $-\mathrm{Co}_{3} \mathrm{O}_{4}-5 \mathrm{~g}$ $\mathrm{Co}\left(\mathrm{NO}_{3}\right)_{2} 6 \mathrm{H}_{2} \mathrm{O}$ (Sigma Aldrich) was dissolved in $20 \mathrm{~cm}^{3}$ of deionized water. The solution was evaporated to dryness and heated at $378 \mathrm{~K}$ for 3 hours. The residue was ground and then calcined at $673 \mathrm{~K}$ for 12 hours. The resulting black solid was reground and then sieved through a $53 \mu \mathrm{m}$ sieve. $\mathrm{NiCo}_{2} \mathbf{O}_{4}-29 \mathrm{~g} \mathrm{Co}\left(\mathrm{NO}_{3}\right)_{2} \cdot 6 \mathrm{H}_{2} \mathrm{O}$ (Sigma Aldrich) and $14.5 \mathrm{~g} \mathrm{Ni}\left(\mathrm{NO}_{3}\right)_{2} \cdot 6 \mathrm{H}_{2} \mathrm{O}$ (Sigma Aldrich) were dissolved in $100 \mathrm{~cm}^{3}$ of deionized water to give a deep red solution. $56 \mathrm{~g} \mathrm{KOH}$ (Sigma Aldrich) and $53.9 \mathrm{~g} \mathrm{NaHCO}_{3}$ (Fisher Scientific) were dissolved in $1500 \mathrm{~cm}^{3}$ of deionized water and the $\mathrm{Ni}(\mathrm{II}) / \mathrm{Co}$ (II) solution was slowly added drop wise to this solution with vigorous stirring. After complete addition, the solution was heated at $353 \mathrm{~K}$ for 20 hours. The green opaque suspension was filtered through a $0.02 \mu \mathrm{m}$ polyamide filter (Whatman) and dried at $373 \mathrm{~K}$. It was then ground before being calcined at $648 \mathrm{~K}$ for 4 hours. The resulting black solid was reground and then sieved through a $53 \mu \mathrm{m}$ sieve.

The spinel structure of both samples was confirmed by XRD (Fig. 2) and the structural parameters are reported in Table I. Elemental analysis of the $\mathrm{NiCo}_{2} \mathrm{O}_{4}$ showed the Ni:Co ratio of 1:2. SEM (Fig. 3) images indicated that the solids were made up of irregular particles with dimensions of $10-50 \mu \mathrm{m}$ while both TEM (Fig. 4) and width of the peaks in the XRD suggest that these particles were, in fact, masses of much smaller crystallites or particles with typical particle size of $10-20 \mathrm{~nm}$. The surface areas measured by BET were $30 \mathrm{~m}^{2} \mathrm{~g}^{-1}$ for $\mathrm{Co}_{3} \mathrm{O}_{4}$ and $68 \mathrm{~m}^{2} \mathrm{~g}^{-1}$ for $\mathrm{NiCo}_{2} \mathrm{O}_{4}$.

The spinel electrocatalysts were formulated as inks. $2 \mathrm{mg}$ spinel was added to $6 \mathrm{~cm}^{3}$ of deionized water and the suspension placed in an
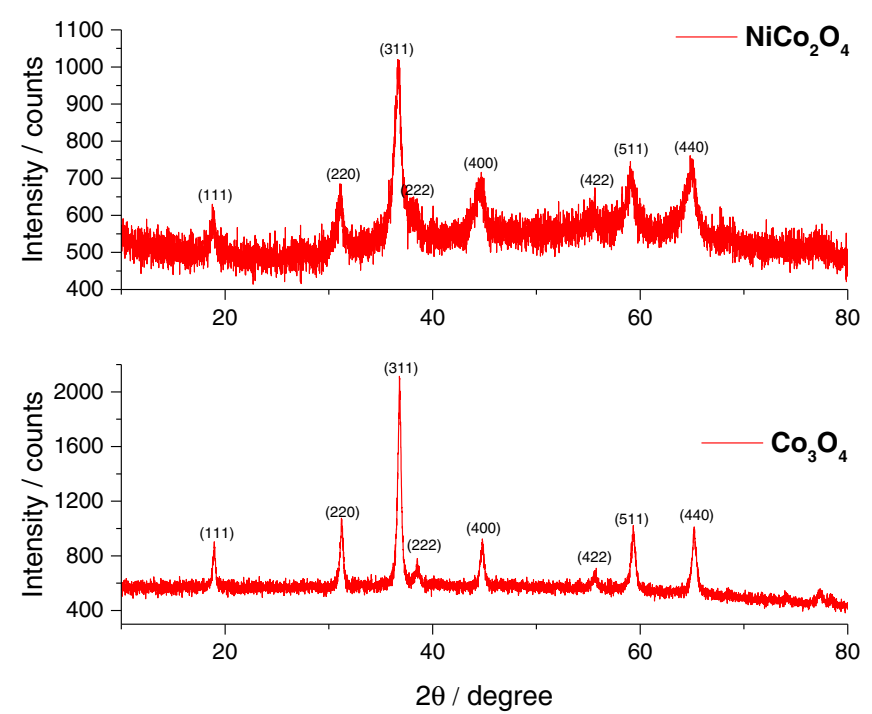

Figure 2. XRD patterns of spinels $\mathrm{Co}_{3} \mathrm{O}_{4}$ (bottom) and $\mathrm{NiCo}_{2} \mathrm{O}_{4}$ (top).
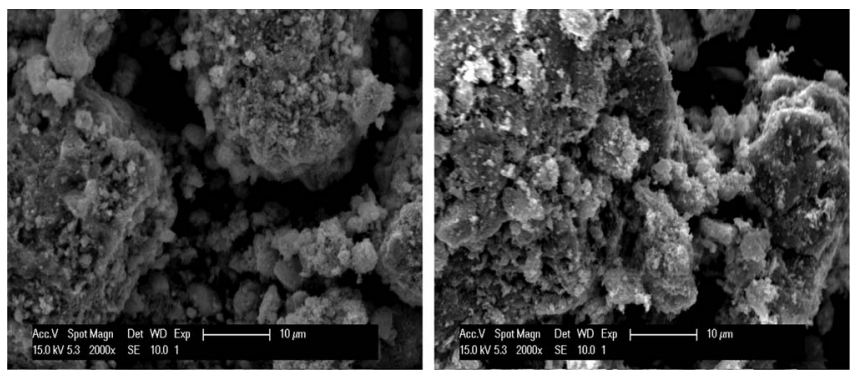

Figure 3. Scanning electron microscope (SEM) of $\mathrm{Co}_{3} \mathrm{O}_{4}$ (left) and $\mathrm{NiCo}_{2} \mathrm{O}_{4}$ (right). Scale bar is 10 micron.

ultrasonic bath (Fisherbrand FB15046) for 30 minutes followed by 2 minutes shear force stirring in a homogenizer (Fisher Powergen 1000). The ink was applied to the glassy carbon discs $\left(0.2 \mathrm{~cm}^{2}\right)$ in $3 \times 15$ $\mu l$ aliquots with drying with an IR heat lamp between applications. Finally, a thin film of Nafion was drop cast over the catalyst layer using $15 \mu 1$ of $1 \mathrm{wt} \%$ Nafion in water (prepared from aqueous Nafion solution, $10 \%$ solids (Ion Power $\mathrm{GmbH}$ )) and the coating again dried. This final layer was found to greatly enhance the stability of the coating and to improve the reproducibility of experimental data. In contrast to many papers in the literature, these spinel catalyzed layers do not contain graphitic carbon powder. Voltammograms of the $\mathrm{Co}_{3} \mathrm{O}_{4}$ and $\mathrm{NiCo}_{2} \mathrm{O}_{4}$ catalysts used in this study in nitrogen purged $1 \mathrm{M} \mathrm{KOH}$ have been previously reported. ${ }^{18}$

For comparison purposes, coatings were prepared either with $\mathrm{Pt}$ black (Fuel Cell Grade) from E-TEK or XC-72R carbon powder
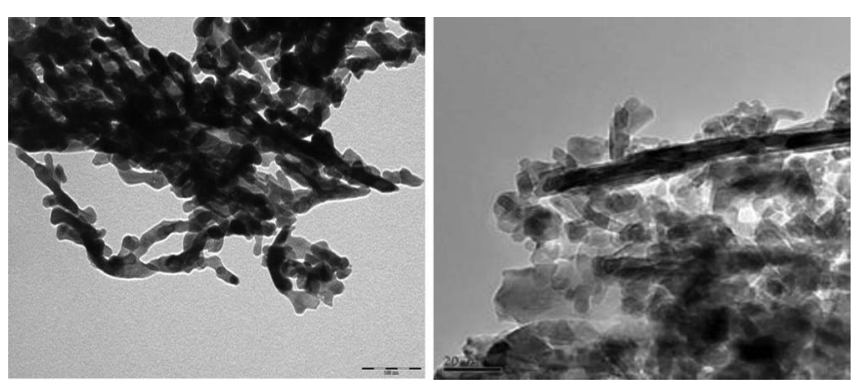

Figure 4. Transmission electron microscopy (TEM) of $\mathrm{Co}_{3} \mathrm{O}_{4}$ (left) and $\mathrm{NiCo}_{2} \mathrm{O}_{4}$ (right). Scale bar: 100nm (left) and $20 \mathrm{~nm}$ (right). 


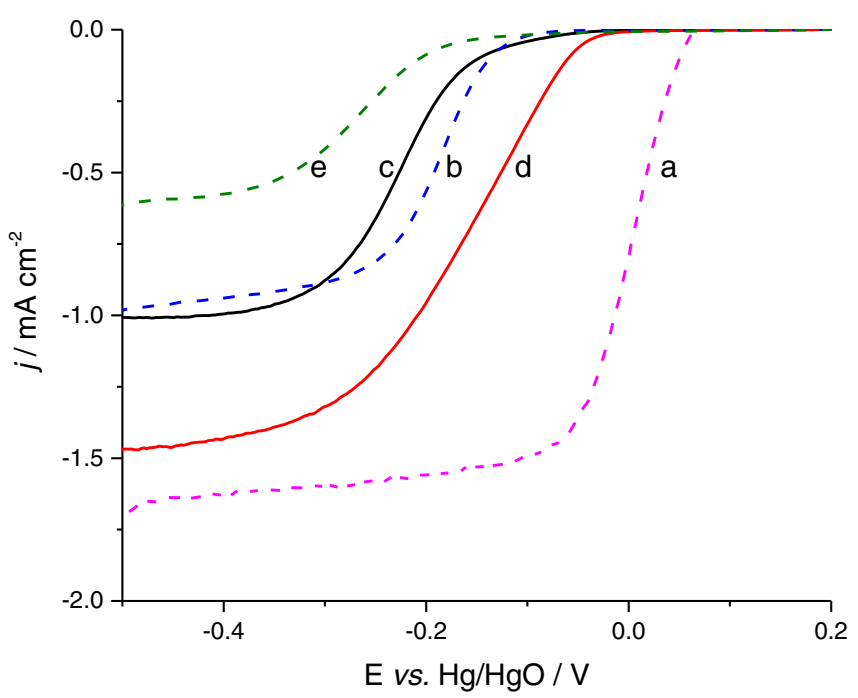

Figure 5. Voltammograms at coated glassy carbon $\mathrm{RDE}$ in $\mathrm{O}_{2}$ saturated $1 \mathrm{M}$ KOH. (a) Pt black (b) XC-72R Carbon powder (c) $\mathrm{Co}_{3} \mathrm{O}_{4}$ (d) $\mathrm{NiCo}_{2} \mathrm{O}_{4}$ (e) Bare GC electrode. Temperature $298 \mathrm{~K}$. Rotation rate $400 \mathrm{rpm}$. Potential scan rate $5 \mathrm{mV} \mathrm{s}^{-1}$.

replacing the spinel catalyst, but otherwise prepared by the same procedure. In all cases, the catalyst loading was $\sim 75 \mu \mathrm{g} \mathrm{cm}^{-2}$.

\section{Results}

Rotating disc electrode (RDE) studies of oxygen reduction.Figure 5 compares voltammograms for $\mathrm{O}_{2}$ reduction in $1 \mathrm{M} \mathrm{KOH}$ at a temperature of $298 \mathrm{~K}$ at four catalyst layers and an uncoated glassy carbon disc, each recorded with a rotation rate of $400 \mathrm{rpm}$. With each electrode, a well-formed sigmoidal reduction wave is obtained but the overpotentials and limiting currents differ significantly, see Table II. Reduction of oxygen does occur at the uncoated glassy carbon disc, as has been previously reported in the literature ${ }^{34-36}$ but it is immediately apparent that the spinel coatings lead to a positive shift in the reduction potential and, in some cases, a large increase in limiting current density. The voltammogram at the Pt black coated electrode is included to allow comparison with the response of a catalyst known to yield the $4 \mathrm{e}^{-}$reduction of $\mathrm{O}_{2}$. Although the spinel catalyzed coatings in our programe do not contain carbon powder, the response at XR-72 is important to this work as it defines the response at a particle-based coating supporting a $2 \mathrm{e}^{-}$mechanism ${ }^{37}$ similar to the spinel coating studied in this paper. High area carbon, which is often added to the catalyst ink to improve conductivity and/or the gas diffusion characteristics of the catalyst layer, may influence the response and this is often unrecognized in papers in the literature.

A number of important aspects should be noted:

i Pt black is the best catalyst for $\mathrm{O}_{2}$ reduction in these conditions but the overpotential at $\mathrm{NiCo}_{2} \mathrm{O}_{4}$ is larger only by $\sim 110 \mathrm{mV}$ at low current densities (i.e. at potentials where a gas diffusion electrode would be expected to operate); values of the potential for a current density of $-0.1 \mathrm{~mA} \mathrm{~cm}{ }^{-2}$ are reported in Table II.

ii The fuel cell grade XC-72 carbon powder based layer (without other catalyst) shows only a moderate increase in overpotential compared to Pt black but with a limiting current density half that for the Pt black coating. The response of the XC-72 stresses the importance of checking the activity of any carbon component in all studies that employ catalyst layers that contain graphitic carbon as well as that of the electrocatalyst. The graphitic carbon can contribute to the current and there is the possibility of parallel reaction pathways on the graphitic carbon and catalyst surfaces. This is the reason, along with the likelihood of carbon corrosion in the conditions for $\mathrm{O}_{2}$ evolution, why in this study, carbon powder was not added to the spinel catalyst layers.

iii The limiting current densities vary with the catalyst layer. It is to be expected that the Pt black will support full $4 \mathrm{e}^{-}$reduction and the XC-72 mainly a $2 \mathrm{e}^{-}$reduction (fuel cell electrodes based on carbon have been used for the production of hydrogen peroxide in $\mathrm{NaOH}$ with a charge efficiency of $\sim 80 \%{ }^{37}$ ) and the ratio of the limiting currents is consistent with this expectation. The limiting currents at the spinels differ strongly. At $\mathrm{NiCo}_{2} \mathrm{O}_{4}$, the limiting current is only slightly less than that at Pt black while that at $\mathrm{Co}_{3} \mathrm{O}_{4}$ is similar to that at $\mathrm{XC}-72$. However, this voltammetry alone does not allow one to determine whether this limiting current results from a $2 \mathrm{e}^{-}$reduction or a strongly kinetically limited $4 \mathrm{e}^{-}$reduction, as will be explored further below.

The rotation rate dependence of the voltammograms at the coated discs was further investigated. For all four coatings, well-formed reduction waves were observed at all rotation rates. With Pt black and $\mathrm{XC}-72$ catalyzed coatings, the limiting current densities were proportional to the square root of the rotation rates although the slopes of the Levich plots differed by a factor of two, consistent with $\mathrm{n}=2$ at carbon and $n=4$ at $\mathrm{Pt}$ black. Figure 6 reports the rotation rate dependences of the responses at the two spinel catalyzed coatings. At all rotation rates, a limiting current density is observed and their values are much lower at $\mathrm{Co}_{3} \mathrm{O}_{4}$ than at $\mathrm{NiCo}_{2} \mathrm{O}_{4}$. In a limiting current plateau region, the rate determining step in the electrode reaction can be either mass transport or a chemical step (NOT electron transfer since this would make the current density dependent on potential as in the rising part of the voltammogram). The limiting current densities at both spinel coatings increase with rotation rate but the reduction of oxygen is not fully mass transport limited since plots of limiting current densities versus the square root of rotation rate (not shown) are clearly non-linear.

As the limiting current densities, $j_{L}$, are partially limited by a chemical step, they were further analyzed using the Koutecky-Levich (K-L) equation:

$$
\frac{1}{j_{L}}=\frac{1}{n F k c_{O_{2}}}+\frac{1}{0.62 n F D^{2 / 3} v^{-1 / 6} c_{O_{2}} \omega^{1 / 2}}
$$

where $n$ is the number of electrons $/ \mathrm{O}_{2}$ transferred during reduction, $F$ the Faraday constant, $c_{\mathrm{O}_{2}}$ the concentration of oxygen in the electrolyte, $D$ the diffusion coefficient of $\mathrm{O}_{2}, \nu$ the kinematic viscosity of the electrolyte and $\omega$ the rotation rate of the disc. $k$ is the rate constant for the chemical step in the reduction mechanism. Thus, the

Table II. Comparison of catalyst materials RDE and RRDE data. $\mathrm{O}_{2}$ saturated $1 \mathrm{M}$ KOH. $298 \mathrm{~K} .400$ rpm. $\S$ data taken for voltammograms recorded at $400 \mathrm{rpm}$. Slopes and intercepts for all materials shown in the table are only from first three points, corresponding to rotation rates of $100,400$ and $900 \mathrm{rpm})$.

RDE data $a^{\S}$

\begin{tabular}{|c|c|c|c|c|c|c|}
\hline \multirow[b]{2}{*}{ Catalyst } & & & \multirow[b]{2}{*}{$\% \mathrm{H}_{2} \mathrm{O}_{2}{ }^{\S}$} \\
\hline & $\mathrm{E}_{-0.1 \mathrm{~mA} \mathrm{~cm}}-2$ vs $\mathrm{Hg} / \mathrm{HgO} / \mathrm{mV}$ & $\mathrm{E}_{3 / 4}-\mathrm{E}_{1 / 4} / \mathrm{mV}$ & $j_{\mathrm{L}} / \mathrm{mA} \mathrm{cm}^{-2}$ & Slope $/ \mathrm{mA}^{-1} \mathrm{~cm}^{2} \mathrm{rpm}^{-1 / 2}$ & Intercept $/ \mathrm{mA}^{-1} \mathrm{~cm}^{2}$ & \\
\hline Pt black & +50 & -53.7 & $-1.6( \pm 0.1)$ & $-11.0( \pm 0.1)$ & $-0.06( \pm 0.01)$ & $<1$ \\
\hline $\mathrm{XC}-72 \mathrm{R} \mathrm{C}$ & -137 & -63.3 & $-1.0( \pm 0.1)$ & $-17.0( \pm 0.3)$ & $-0.16( \pm 0.02)$ & $57( \pm 3)$ \\
\hline $\mathrm{Co}_{3} \mathrm{O}_{4}$ & -149 & -75.8 & $-1.0( \pm 0.1)$ & $-13.1( \pm 0.5)$ & $-0.32( \pm 0.03)$ & $36( \pm 2)$ \\
\hline $\mathrm{NiCO}_{2} \mathrm{O}_{4}$ & -61 & -117 & $-1.5( \pm 0.1)$ & $-10.2( \pm 0.3)$ & $-0.16( \pm 0.02)$ & $6( \pm 0.3)$ \\
\hline
\end{tabular}



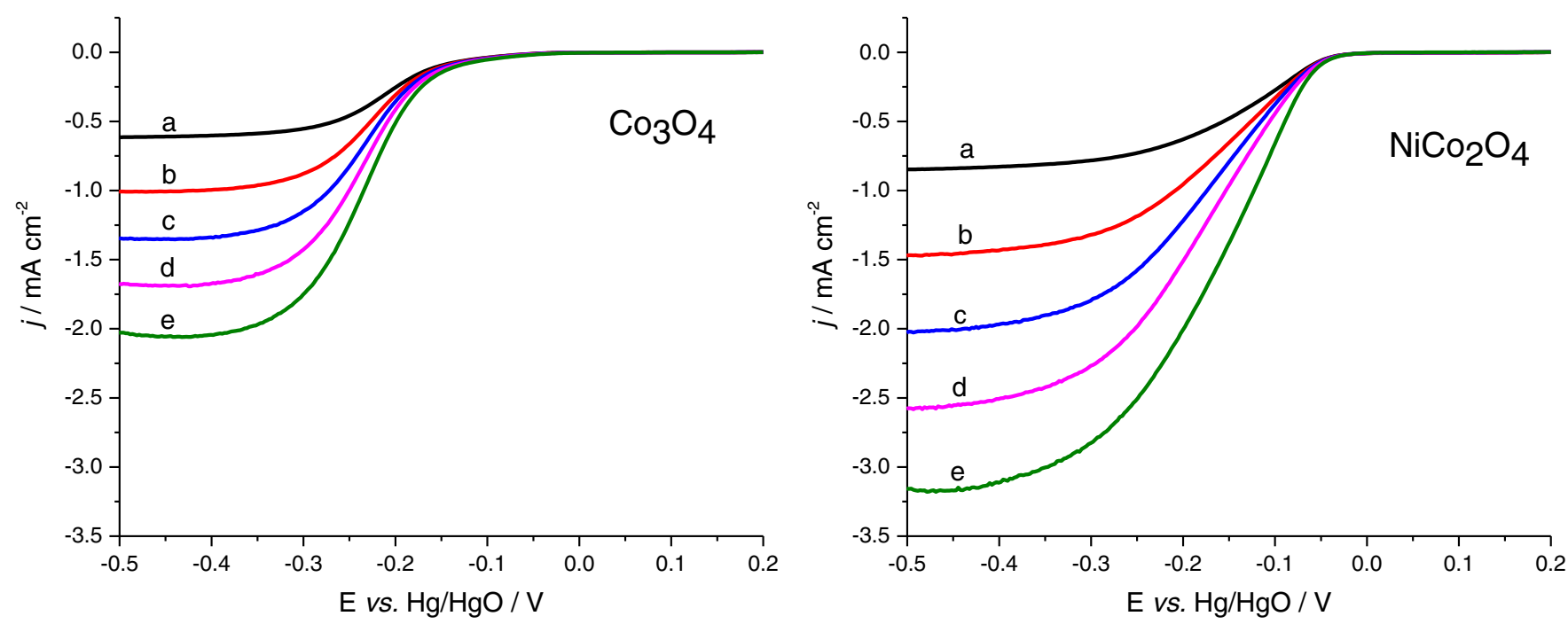

Figure 6. Rotation rate dependence of the voltammograms for the reduction of $\mathrm{O}_{2}$ in $1 \mathrm{M} \mathrm{KOH}$ at $\mathrm{Co}_{3} \mathrm{O}_{4}$ and $\mathrm{NiCo}_{2} \mathrm{O}_{4}$ electrodes. Rotation rates (a) 100 rpm (b) $400 \mathrm{rpm}$ (c) $900 \mathrm{rpm}$ (d) $1600 \mathrm{rpm}$ and (e) $2500 \mathrm{rpm}$. Temperature $298 \mathrm{~K}$. Potential scan rate $5 \mathrm{mV} \mathrm{s}^{-1}$. The surface area of glassy carbon disc is $0.2 \mathrm{~cm}^{2}$.

comparative values of the slopes provide information about the number of electrons involved in the reduction while the intercepts reflect the rate of the chemical step.

Figure 7 shows plots of $1 / j_{L}$ vs $1 / \omega^{1 / 2}$ for the four coated electrodes and the slopes and intercepts from these plots are reported in Table II. The K-L plots for the Pt black and XC-72 carbon catalyzed coatings are linear and have only a small intercept on the $1 / j_{L}$ axis, but have different slopes, as expected. This is consistent with mass transport limited currents but different values of $n$. The linear fit through the data points at low rotation rates for $\mathrm{Co}_{3} \mathrm{O}_{4}$ and $\mathrm{NiCo}_{2} \mathrm{O}_{4}$ shown in Figure 7 goes through the first 3 or 4 points, but there is deviation to this linear fit at high rotation rates (small values of $1 / \omega^{1 / 2}$ ), which is particularly marked for $\mathrm{Co}_{3} \mathrm{O}_{4}$ at high rotation rates. The slopes of these linear fits at low rotation rates are similar to that obtained for Pt black, confirming that the reduction at the spinels involve $4 \mathrm{e}^{-}$. For both spinels, the lines have a clear non-zero intercept on the $1 / j_{L}$ axis confirming a component of kinetic control to the limiting currents. The intercept for $\mathrm{Co}_{3} \mathrm{O}_{4}$ is substantially larger than that for $\mathrm{NiCo}_{2} \mathrm{O}_{4}$, indicating that the chemical step is slower at this spinel. The deviation at high rotation rates is probably due to a greater involvement of a $2 \mathrm{e}^{-}$ mechanism as also evident by the increase in slope (Table II).

Rotating ring disc electrode (RRDE) studies of oxygen reduction: The extent of hydrogen peroxide formation as an intermediate in oxygen reduction was also investigated with catalyst coated glassy carbon disc/Pt ring (RRDE) electrodes (collection efficiency 0.37). The potential of the disc was scanned through the potential range for $\mathrm{O}_{2}$ reduction while the ring potential was held at $+200 \mathrm{mV}$ vs $\mathrm{Hg} / \mathrm{HgO}$, a potential where the oxidation of hydrogen peroxide is mass transport controlled on $\mathrm{Pt}^{38}$ Figure 8 shows sets of responses for $\mathrm{Co}_{3} \mathrm{O}_{4}$ and $\mathrm{NiCo}_{2} \mathrm{O}_{4}$ catalyzed disc electrodes while the data for these electrodes as well as XC-72 and Pt black are summarized in Table II by reporting the \% of the reduction current that leads to hydrogen peroxide. While some hydrogen peroxide is detected with both spinel catalyzed electrodes, the magnitudes of the ring currents with the two spinels are very different. With $\mathrm{NiCo}_{2} \mathrm{O}_{4}$, hydrogen peroxide collected at the ring represents a very low current efficiency for hydrogen peroxide, $6 \%$ at $400 \mathrm{rpm}$. Indeed, SEM images of the edges of the coated discs (not shown) revealed that in some cases there
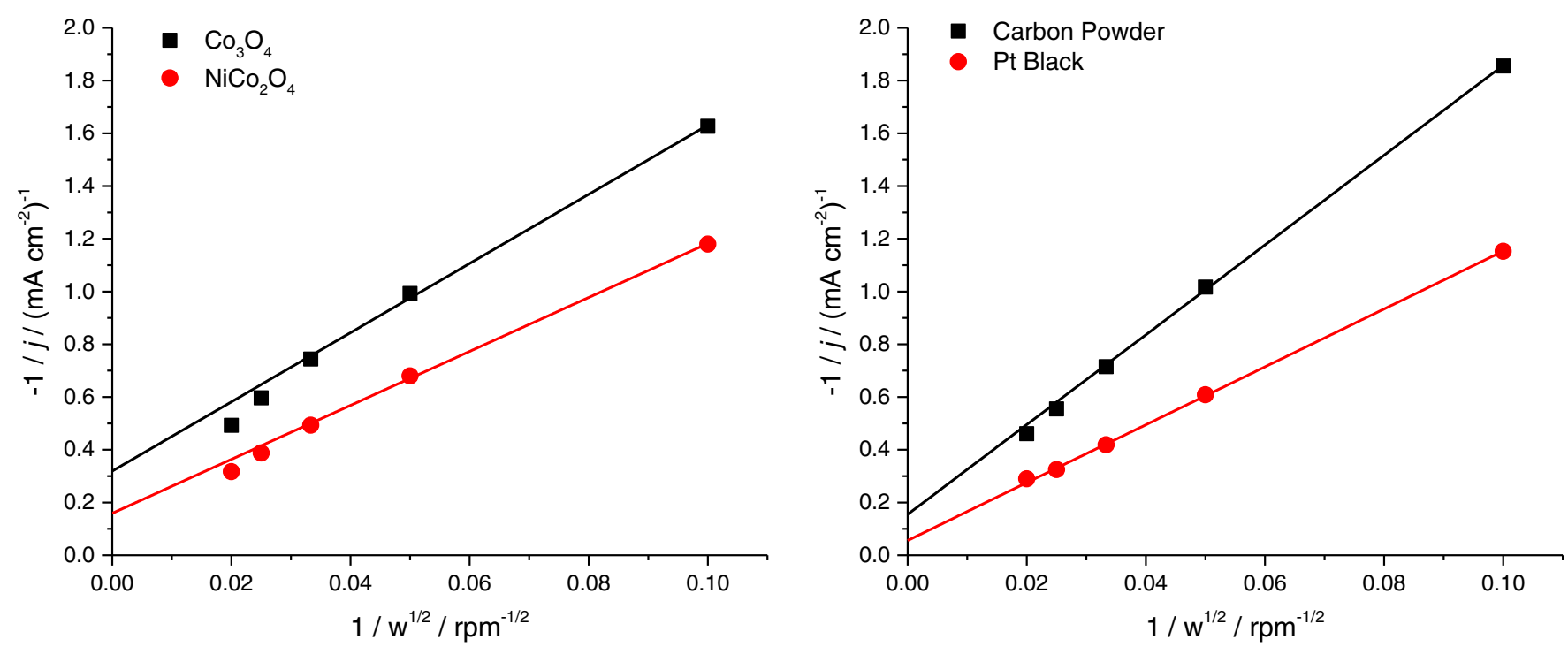

Figure 7. Koutecky-Levich plots for $\mathrm{O}_{2}$ reduction in $1 \mathrm{M} \mathrm{KOH}$ with $\mathrm{Co}_{3} \mathrm{O}_{4}, \mathrm{NiCo}_{2} \mathrm{O}_{4}$, carbon powder (XC-72R), Pt black coatings on glassy carbon. Data taken at $-500 \mathrm{mV}$ vs $\mathrm{Hg} / \mathrm{HgO}$, in the plateau regions of the voltammograms. $1 \mathrm{M} \mathrm{KOH}$. Temperature $298 \mathrm{~K}$. Scan rate $5 \mathrm{mV} \mathrm{s}^{-1}$. Lines shown are best fits through only the three lowest rotation rates $(100,400$, and $900 \mathrm{rpm})$, as discussed in the text. 

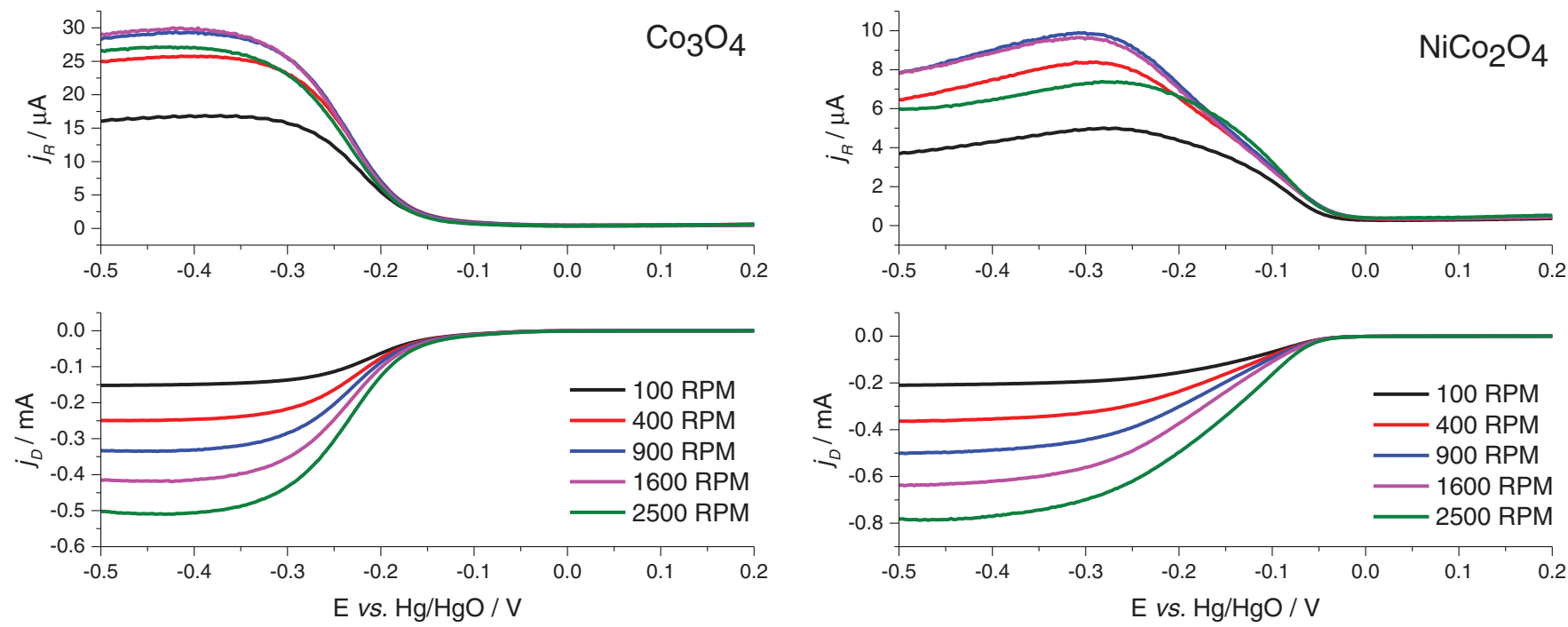

Figure 8. Disc and ring responses for $\mathrm{O}_{2}$ reduction at $\mathrm{Co}_{3} \mathrm{O}_{4}$ and $\mathrm{NiCo}_{2} \mathrm{O}_{4}$ coated glassy carbon discs. The potential of the discs is scanned while the Pt ring electrode is held at $+200 \mathrm{mV}$ vs $\mathrm{Hg} / \mathrm{HgO}$. Rotation rates as shown. $\mathrm{O}_{2}$ saturated $1 \mathrm{M} \mathrm{KOH}$. Temperature $298 \mathrm{~K}$. Potential scan rate $5 \mathrm{mV} \mathrm{s}{ }^{-1}$. The disc area: $0.25 \mathrm{~cm}^{2}$; The ring area: $0.19 \mathrm{~cm}^{2}$. The collection efficiency of the RRDE is 0.37 .

was uncovered glassy carbon close to the PTFE surround, and such exposed substrate could easily account for the small amount hydrogen peroxide formation observed. In contrast, at the $\mathrm{Co}_{3} \mathrm{O}_{4}$ based coating, hydrogen peroxide formation at the catalyst particles on the disc becomes a significant contributor to the disc current, 36\% at $400 \mathrm{rpm}$.

The results with XC-72 and Pt black are consistent with the literature. The formation of hydrogen peroxide is a very minor contribution at the Pt black thin film electrode $(<1 \%)$, while with the XC-72R carbon it becomes the major reaction; for the carbon electrode $57 \%$ of the charge at the disc leads to $\mathrm{H}_{2} \mathrm{O}_{2}$ and this is to be expected from the known performance of $\mathrm{C}$ based GDEs ${ }^{37}$

RDE studies of hydrogen peroxide oxidation and reduction.Figure 9 compares the voltammograms at $\mathrm{Co}_{3} \mathrm{O}_{4}$ and $\mathrm{NiCo}_{2} \mathrm{O}_{4}$ catalyzed disc electrodes for a solution of hydrogen peroxide in $1 \mathrm{M}$ $\mathrm{KOH}$. At both electrodes, both reduction and oxidation of hydrogen peroxide is observed but the current densities for reduction are smaller than for oxidation (both oxidation to oxygen and reduction to hydroxide involves $2 \mathrm{e}^{-}$and the mass transport controlled current densities

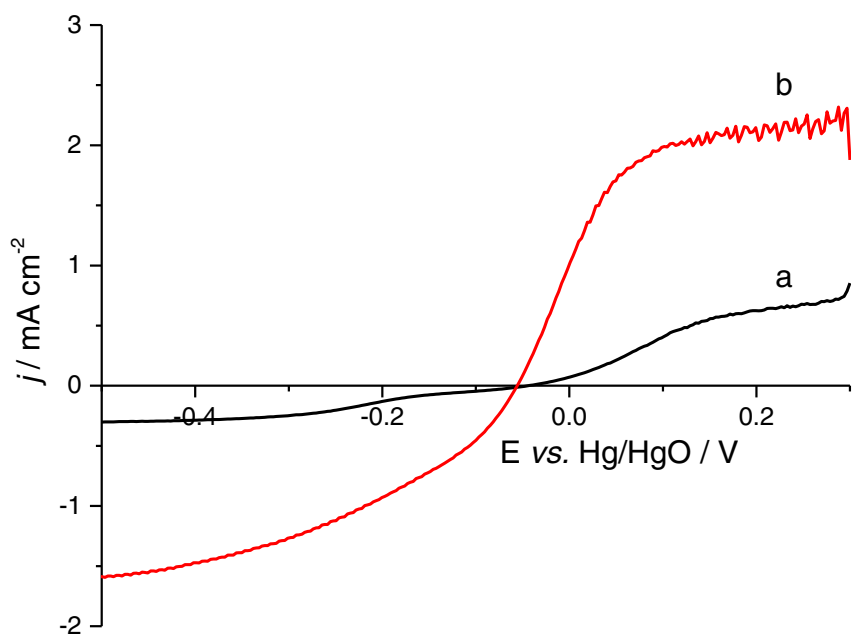

Figure 9. Voltammograms at glassy carbon RDE coated with (a) $\mathrm{Co}_{3} \mathrm{O}_{4}$ (b) $\mathrm{NiCo}_{2} \mathrm{O}_{4}$ for $\sim 10 \mathrm{mM} \mathrm{H}_{2} \mathrm{O}_{2}$ in $\mathrm{N}_{2}$ purged, $1 \mathrm{M} \mathrm{KOH}$. Temperature $298 \mathrm{~K}$. Rotation rate $400 \mathrm{rpm}$. Potential scan rate $1 \mathrm{mV} \mathrm{s}^{-1}$. would be equal). Even the oxidation limiting currents are not mass transport controlled (the limiting currents are not proportional to the square root of rotation rate) and all the currents are low compared those expected for the estimated concentration of hydrogen peroxide. The limiting current for the reduction is almost independent of the rotation rate of the disc confirming the strong kinetic limitation to the reduction of hydrogen peroxide at these spinels. Clearly, with a slow rate for the reduction of $\mathrm{H}_{2} \mathrm{O}_{2}$ at the spinel coatings, a $2 \mathrm{e}^{-}+2 \mathrm{e}^{-}$ mechanism for a $4 \mathrm{e}^{-}$reduction is unlikely.

\section{Discussion}

Transition metal oxide electrocatalysts have been subjected to substantial study as alternative catalysts to precious metals for $\mathrm{O}_{2}$ reduction. ${ }^{1-6,33}$ Many such oxides are easy to prepare from cheap starting materials and they can be conductive and sometimes show electrocatalytic activity for $\mathrm{O}_{2}$ reduction. The spinels, $\mathrm{Co}_{3} \mathrm{O}_{4}$ and $\mathrm{NiCo}_{2} \mathrm{O}_{4}$, are both conductive and straightforward to prepare from aqueous nitrate solutions. They may also be formulated into catalyst layers free of graphitic carbon powder on an inert RDE.

In our studies, $\mathrm{Co}_{3} \mathrm{O}_{4}$ and $\mathrm{NiCo}_{2} \mathrm{O}_{4}$ in alkaline electrolytes show very different properties as $\mathrm{O}_{2}$ reduction electrocatalysts. $\mathrm{NiCo}_{2} \mathrm{O}_{4}$ is an effective catalyst; it supports the full $4 \mathrm{e}^{-}$reduction (as $\mathrm{Pt}$ ) at a rate approaching mass transport control, although with a slightly larger overpotential than Pt. In contrast, the $\mathrm{Co}_{3} \mathrm{O}_{4}$ coating is a poor catalyst for $\mathrm{O}_{2}$ reduction. The voltammetry also suggests a $4 \mathrm{e}^{-}$reduction in some mass transport conditions, but it also implies a slow step in the $4 \mathrm{e}^{-}$pathway (presumably the initial cleavage of the $\mathrm{O}-\mathrm{O}$ bond) allowing the $2 \mathrm{e}^{-}$pathway to compete particularly at high rates of convection. Thus at $\mathrm{Co}_{3} \mathrm{O}_{4}$ coatings, the limiting currents are substantially below those for a mass transfer controlled $4 \mathrm{e}^{-}$reaction and then only with a higher overpotential while RRDE studies confirm a substantial fraction of the charge passed leads to hydrogen peroxide. Literature reviews ${ }^{1-5}$ agree that the cobalt spinel is a poor $\mathrm{O}_{2}$ reduction catalyst and, indeed, a review of cobalt spinel electrocatalysts ${ }^{2}$ makes no mention of the parent cobalt spinel in the section on oxygen reduction. On the other hand, Heller-Ling et al. ${ }^{14}$ conclude that a $\mathrm{Co}_{3} \mathrm{O}_{4}$ coating catalyzed the full $4 \mathrm{e}^{-}$reduction and imply a limiting current indicating mass transfer control; the reason for the discrepancy with the work reported herein is not clear. In addition, several recent papers ${ }^{22-24,30,32}$ report studies on electrode coatings containing nanostructured $\mathrm{Co}_{3} \mathrm{O}_{4}$ and some show good oxygen reduction activity. The recently reported activity of $\mathrm{Co}_{3} \mathrm{O}_{4}$ nanochains ${ }^{32}$ is particularly 
impressive. But all these coatings contain an active carbon, a graphitic carbon powder or graphene, and, in general, papers do not define the role of these additional materials. It remains possible, however, that the nanostructured $\mathrm{Co}_{3} \mathrm{O}_{4}$ can have a high density of the actual catalyst sites promoting the cleavage of the $\mathrm{O}-\mathrm{O}$ bond.

As noted in the Introduction, the full $4 \mathrm{e}^{-}$reduction can occur by two types of pathway, one not involving $\mathrm{H}_{2} \mathrm{O}_{2}$ and probably involving the early cleavage of the O-O bond and another where $\mathrm{H}_{2} \mathrm{O}_{2}$ is formed but rapidly converted to hydroxide by reduction or disproportionation on the catalyst surface. The two reaction pathways will always compete with the more rapid dominating.

With the $\mathrm{NiCO}_{2} \mathrm{O}_{4}$ catalyst, the RDE data is generally consistent with $\mathrm{O}_{2}$ reduction in a full $4 \mathrm{e}^{-}$reduction and the RRDE experiments show, at most, only a very low formation of $\mathrm{H}_{2} \mathrm{O}_{2}$. The sluggish cathodic reduction of $\mathrm{H}_{2} \mathrm{O}_{2}$ at $\mathrm{NiCo}_{2} \mathrm{O}_{4}$ seems to rule out reaction pathways for $\mathrm{O}_{2}$ reduction where $\mathrm{H}_{2} \mathrm{O}_{2}$ is formed and rapidly further reduced. Hence, we believe that at $\mathrm{NiCo}_{2} \mathrm{O}_{4}, \mathrm{O}_{2}$ reduction occurs via a mechanism where the $\mathrm{O}-\mathrm{O}$ bond is cleaved in an initial step. The Levich and Koutecky-Levich plots confirm that $\mathrm{O}_{2}$ reduction is never fully mass transport controlled and even in the limiting current plateau it is partially kinetically controlled by the rate of this $\mathrm{O}-\mathrm{O}$ cleavage reaction. The use of high rotation rates will put more pressure on the chemical step leading to cleavage of the $\mathrm{O}-\mathrm{O}$ bond and this will lead to an increased opportunity for electron transfer as the first step and hence for the formation of $\mathrm{H}_{2} \mathrm{O}_{2}$ in a $2 \mathrm{e}^{-}$step and the slight deviation from linearity in K-L plot for this spinel. The voltammetry at XC-72 carbon shows that electron addition to $\mathrm{O}_{2}$ occurs at potentials only slightly negative to those for catalytic mechanism.

The responses with $\mathrm{Co}_{3} \mathrm{O}_{4}$ are consistent with a similar mechanism, but correspond to a system where the chemical step is much slower. Hence, the $2 \mathrm{e}^{-}$has a greater role. The RRDE experiment shows substantial $\mathrm{H}_{2} \mathrm{O}_{2}$ formation and the Koutecky-Levich plot has a larger intercept. The K-L plot for the limiting currents at lower rotation rates also suggest a $4 \mathrm{e}^{-}$reduction but there is a larger deviation of the slope toward that for a $2 \mathrm{e}^{-}$reduction at higher rotation rates.

Thus it appears that two reaction pathways for $\mathrm{O}_{2}$ reduction occur in parallel and at intermediate rate constants for the chemical step, the relative importance of the two mechanisms changes with mass transport conditions; increasing the rate of convection will put greater pressure on the chemical step in the direct $4 \mathrm{e}^{-}$reduction. It is tempting to propose, more generally, that electron transfer is the "default mechanism" when the rate of O-O cleavage is slow. The potentials for electron addition to $\mathrm{O}_{2}$ are only slightly negative to that for the direct $4 \mathrm{e}^{-}$reduction initiated by a chemical step such as $\mathrm{O}-\mathrm{O}$ bond cleavage; the potential of direct $4 \mathrm{e}^{-}$reduction will, of course, depend critically on the electrocatalyst and the kinetics of the chemical step on its surface. Certainly, with catalytic layers containing both active carbon powder and another catalyst, it is possible that the two mechanisms occur in competition with the relative importance of the two routes depending on the rate of $\mathrm{O}-\mathrm{O}$ cleavage at the other catalyst.

Further investigations are necessary. From the literature and unpublished studies in our laboratory, we are aware that spinel catalysts prepared by different routes and using different conditions within a single route show some variation in the rate of $\mathrm{O}_{2}$ reduction but the reasons cannot be deduced from the information available (perhaps a result of different crystallite sizes or small variations in $\mathrm{Ni} / \mathrm{Co} / \mathrm{O}$ ratios, etc.). For this reason, we would stress that it must be recognized that the literature on each spinel with nominally the same composition in fact represents the behavior and performance of a related family of materials. Perhaps an even more important question is why the overpotential and limiting current for $\mathrm{O}_{2}$ reduction are sensitive to choice and ratio of transition metals in the spinel. Both questions are the subject of further study.

\section{Conclusions}

The reduction of oxygen at cathodes catalyzed by $\mathrm{NiCo}_{2} \mathrm{O}_{4}$ occurs predominantly by a $4 \mathrm{e}^{-}$reaction leading to water without the intermediate formation of hydrogen peroxide. The rate limitation is controlled by a chemical step, most likely the cleavage of the $\mathrm{O}-\mathrm{O}$ on the surface of the spinel. The reduction at $\mathrm{Co}_{3} \mathrm{O}_{4}$ occurs with lower current densities. The rate of the cleavage reaction and hence the $4 \mathrm{e}^{-}$ reduction is much slower and this leads to a significant contribution from a competing mechanism, initial electron transfer to the oxygen molecule; almost half the charge passed leads to hydrogen peroxide formation. The literature shows that some nanostructured $\mathrm{Co}_{3} \mathrm{O}_{4}$ materials are more active for the $4 \mathrm{e}^{-}$implying a much higher density of active sites on those materials.

\section{Acknowledgments}

Part of this work was carried out using financial support by the European Commission (Theme 2010.7.3.1) Energy Storage Systems for Power Distribution Networks, grant Agreement No. 256759, and this support is gratefully acknowledged. The SEM instrument was funded by the EPSRC through grant reference EP/K039466/1. TS acknowledge the receipt of a studentship from the Ministry of National Education, Republic of Turkey.

\section{References}

1. K. Kinoshita, Electrochemical Oxygen Technology, John Wiley \& Sons Inc. 1992.

2. M. Hamdani, R. N. Singh, and P. Chartier, " $\mathrm{Co}_{3} \mathrm{O}_{4}$ and Co-based spinel oxides bifunctional oxygen electrodes," Int. J. Electrochem. Sci., 5, 556 (2010).

3. L. Jòrissen, "Bifunctional oxygen/air electrodes," J. Power Sources, 15523 (2006).

4. V. Nikolova, P. Iliev, K. Petrov, T. Vitanov, E. Zhecheva, R. Stoyanova, I. Valov, and D. Stoychev, "Electrocatalaysts for bifunctional oxygen/air electrodes," J. Power Sources, 185, 727 (2008)

5. V. Neburchilov, H. Wang, J. J. Martin, and W. Qu, "A review on air cathodes for zinc-air fuel cells," J. Power Sources, 195, 1271 (2010).

6. Handbook of Fuel Cells, Volume 2, Eds. W. Vielstich, H. A. Gasteiger, and A. Lamm, John Wiley, New York, 2003.

7. M. R. Tarasevich, A. Sadkowski, and E. Yeager, Oxygen Electrochemistry, Chapter 6 p 301, Comprehensive Treatise of Electrochemistry, Volume 7, Eds. B. E. Conway, J. O'M. Bockris, E. Yeager, S. U. M. Khan, and R. E. White, Plenum Press, New York, 1983.

8. V. S. Bagotsky, M. R. Tarasevich, and V. Yu. Felinovskii, "Calculation of the kinetic parameters of conjugated reactions of $\mathrm{O}_{2}$ and $\mathrm{H}_{2} \mathrm{O}_{2}$," Soviet Electrochem., 5, 1158 (1969).

9. S. P. Jiang, Z. G. Lin, and A. C. C. Tseung, "Homogeneous and heterogeneous catalytic reactions in cobalt oxide/graphite air electrodes II Homogeneous role of Co(II) ions during oxygen reduction on $\mathrm{Co}_{3} \mathrm{O}_{4} /$ graphite electrodes," J. Electrochem. Soc., 137, 764 (1990)

10. S. P. Jiang and A. C. C. Tseung, "Homogeneous and heterogeneous catalytic reactions in cobalt oxide/graphite air electrodes III Deposition of cobalt oxide catalysts onto graphite electrodes for oxygen reduction," J. Electrochem. Soc., 137, 3442 (1990).

11. A. C. C. Tseung and K. L. K. Yeung, "Reduction of oxygen on Teflon-bonded $\mathrm{NiCo}_{2} \mathrm{O}_{4} /$ graphite electrodes," J. Electrochem. Soc., 125, 1003 (1978).

12. W. J. King and A. C. C. Tseung, "The reduction of oxygen on nickel-cobalt oxides I. The Influence of Composition and Preparation Method on the Activity of NickelCobalt Oxides," Electrochim Acta, 19, 485 (1974).

13. W. J. King and A. C. C. Tseung, "The reduction of oxygen on nickel-cobalt oxides. II. Correlation between crystal structure and activity of $\mathrm{Co}_{2} \mathrm{NiO}_{4}$ and related oxides," Electrochim Acta, 19, 493 (1974)

14. N. Heller-Ling, M. Pretsat, J. L. Gautier, J-F. Koenig, G. Poillerat, and P. Chartier, "Oxygen electroreduction mechanism at thin $\mathrm{Ni}_{\mathrm{x}} \mathrm{Co}_{3-\mathrm{x}} \mathrm{O}_{4}$ spinel films in a double channel electrode flow cell (DCEFC)," Electrochim. Acta, 42, 197 (1997)

15. X-Z. Yuan, W. Qu, X. Zhang, P. Yao, and J. Fahlman, "Spinel $\mathrm{Ni}_{\mathrm{x}} \mathrm{Co}_{2-\mathrm{x}} \mathrm{O}_{4}$ as a bifunctional air electrode for zinc-air batteries," ECS Trans., 45(29), 105 (2013).

16. X. Li, D. Pletcher, A. E. Russell, F. C. Walsh, R. G. A. Wills, S. F. Gorman, S. W. T. Price, and S. J. Thompson, "A novel bifunctional oxygen GDE for alkaline batteries," Electrochem. Commun., 34, 228 (2013).

17. S. W. T. Price, S. J. Thompson, X. Li, S. F. Gorman, D. Pletcher, A. E. Russell, F. C. Walsh, and R. G. A. Wills, "The fabrication of a bifunctional oxygen GDE without carbon components for alkaline secondary batteries," J. Power Sources, 259, 43 (2014)

18. D. Pletcher, X. H. Li, S. W. T. Price, A. E. Russell, T. Sonmez, and S. J. Thompson, "Comparison of the Spinels $\mathrm{Co}_{3} \mathrm{O}_{4}$ and $\mathrm{NiCO}_{2} \mathrm{O}_{4}$ as Bifunctional Oxygen Catalysts in Alkaline Media," Electrochim. Acta, 188, 286 (2016).

19. S. Malkhandi, P. Trinh, A. K. Manohar, K. C. Jayachandrababu, A. Kindler, G. K. Surya Prakash, and S. R. Narayanan, "Electrocatalytic activity of transition metal oxide-carbon composites for oxygen reduction in alkaline batteries," J. Electrochem. Soc., 160, F943 (2013)

20. T. Poux, F. S. Napolskiy, T. Dintzer, G. Kéranguéven, S. Y. Istomin, G. A. Tsirlina, E. A. Antipov, and E. R. Savinova, "Dual role of carbon in the catalytic layers of 
perovskite/carbon composites for the electrolytic oxygen reduction reaction," Catal. Today, 189, 83 (2012).

21. S. Müller, F. Holzer, H. Arai, and O. Haas, "A study of carbon catalyst interaction in bifunctional air electrodes for zinc-air batteries," J. New Mater. Electrochem. Systems, 2, 227 (1999)

22. Y. Liang, Y. Li, H. Wang, J. Zhou, J. Wang, and T. Regierand H. Dai, " $\mathrm{Co}_{3} \mathrm{O}_{4}$ nanocrystals on graphene as a synergistic catalyst for oxygen reduction reaction," Nature Mater, 10, 780 (2011).

23. J. $\mathrm{Xu}, \mathrm{P}$. Gao, and T. S. Zhao, "Non-precious $\mathrm{Co}_{3} \mathrm{O}_{4}$ nanorod electrocatalyst for oxygen reduction reaction in anion-exchange membrane fuel cells," Energy Environ. Sci, 5, 5333 (2011).

24. Y. J. Sa, K. Kwon, J. Y. Cheon, F. Kleitz, and S. H. Joo, "Ordered mesoporous $\mathrm{Co}_{3} \mathrm{O}_{4}$ spinels as stable bifunctional, noble metal free oxygen electrocatalysts," $J$. Mater. Chem. A, 1, 9992 (2013).

25. C. Jin, F. Lu, X. Cao, Z. Yang, and R. Yang, "Facile synthesis and excellent electrochemical properties of $\mathrm{NiCO}_{2} \mathrm{O}_{4}$ spinel nanowire arrays as bifunctional catalyst for the oxygen reduction and evolution reaction," J. Mater. Chem. A, 1, 12170 (2013).

26. D. U. Lee, B. Kim, and Z. Chen, "One-pot synthesis of mesoporous $\mathrm{NiCo}_{2} \mathrm{O}_{4}$ nanoplatelet and graphene hybrid and its oxygen reduction and evolution activities as an efficient bi-functional electrocatalyst," J. Mater. Chem. A, 1, 4754 (2013).

27. Z-Q. Lui, Q-Z. Xu, J-Y. Wang, N. Li, S-H. Guo, Y-Z. Su, H-J. Wang, J-H. Zhang, and $\mathrm{S}$. Chen, "Facile hydrothermal synthesis of urchin-like $\mathrm{NiCo}_{2} \mathrm{O}_{4}$ spheres as efficient electrocatalysts for oxygen reduction reaction," Int. J. Hydrogen Energy, 38, 6657 (2013).

28. M. Prabu, K. Ketpang, and S. Shanmugam, "Hierarchical nanostructured NiCo2O4 as an efficient non-precious metal catalyst for rechargeable zinc-air batteries," Nanoscale, 6, 3173 (2014)
29. J. Shen, X. Li,N. Li, and M. Ye, "Facile synthesis of $\mathrm{NiCo}_{2} \mathrm{O}_{4}$-reduced graphene oxide nanocomposites with improved electrochemical properties," Electrochim. Acta, 141, 126 (2014).

30. F. Kong, "Synthesis of rod and beadlike $\mathrm{Co}_{3} \mathrm{O}_{4}$ and bifunctional properties as air/oxygen electrode materials," Electrochim. Acta, 68, 198 (2012).

31. D. U. Lee, B. J. Kim, and Z. Chen, "One-pot synthesis of a mesoporous $\mathrm{NiCO}_{2} \mathrm{O}_{4}$ nanoplatelet and graphene hybrid and its oxygen reduction and evolution activities as an efficient bi-functional electrocatalyst," J. Mater. Chem. A, 1, 4754 (2013).

32. P. W. Menezes, A. Indra, D. González-Flores, N. R. Sahraie, I. Zaharieva, M. Schwarte, P. Strasser, H. Dau, and M. Driess, "High-performance oxygen redox catalysis with multifunctional cobalt oxide nanochains: morphology-dependent activity," ACS Catalysis, 5, 2017 (2015).

33. J. Suntivich, H. A. Gasteiger, N. Yabuuchi, and Y. Shao-Horn, "Electrocatalytic measurement methodology of oxide catalysts using a thin-film RDE," J. Electrochem. Soc., 157, B1263 (2010).

34. H. Yang and R. L. McCreery, "Elucidation of the Mechanism of Dioxygen Reduction on Metal-Free Carbon Electrodes," J. Electrochem. Soc., 147, 3420 (2000).

35. D. Zhang, J. F. Wu, L. Q. Mao, T. Okajima, K. Kitamura, T. Ohsaka, and T. Solomura, "Hydrodunamic Chronocoulometric Estimation of Diffusion and Saturated Concentration of Dioxygen in KOH Solutions," Indian J. Chem., 42A, 801 (2003).

36. A. Sarapuu, K. Vaik, D. J. Schiffrin, and K. Tammeveski, "Electrochemical Reduction of Oxygen on Anthraquinone Modified Glassy Carbon Electrodes in Alkaline Solution," J. Electroanal. Chem., 541, 23 (2003).

37. P. C. Foller and R. T. Bombard, "Processes for the production of mixtures of caustic soda and hydrogen peroxide via the reduction of oxygen," J. Applied Electrochem., 25, 613 (1995).

38. N. M. Markovic, H. A. Gasteiger, and P. N. Ross, "Oxygen Reduction on platinum low-index single-crystal surfaces in alkaline solution: Rotating ring disk (Pt(hkl)) studies," J. Phys. Chem., 100, 6715 (1996) 